\title{
Sistem Peringatan Dini Banjir Berdasarkan Ketinggian Air, Debit Air Dan Curah Hujan Dilengkapi Dengan Sistem Monitoring Data Sensor
}

\author{
Abdullah $^{1}$, Rizki Fitriana ${ }^{2}$ \\ ${ }^{1}$ Politehnik Negeri Medan ${ }^{2}$ Universitas Islam Negeri Sumatera Utara Medan \\ E-mail: ${ }^{1}$ abdullah@ polmed.ac.id ${ }^{2}$ rizki.fitriana04@gmail.com
}

\begin{abstract}
ABSTRAK
Seringnya sungai meluap pada saat musim hujan dan mengakibatkan banjir sehingga banyak menimbulkan kerugian bagi masyrakat. Oleh sebab itu dirancang sebuah alat monitoring peringatan dini banjir berdasarkan ketinggian permukaan dan intensitas curah hujan. Alat ini dikontruksikan menggunakan kombinasi sensor water level, sensor ultrasonik (SRF-05) dan water flow untuk mengetahui unjuk kerja sistem monitoring permukaan dan debit air sungai serta intensitas curah hujan sebagai peringatan dini banjir, menghasilkan sebuah program hasil monitoring dan mengetahui keefektifan mikrokontroler dalam mengukur dan mengendalikan sistem. Pengujian dilakukan dengan prototype aquarium dan dilakukan pengukuran selama satu hari secara kontinyu. Hasil pengujian menunjukkan bahwa alat ini mampu memonitoring peringatan dini banjir secara efisien. Dengan demikian, alat yang dirancang mampu memonitoring ketinggian aktifitas air, debit serta intensitas curah hujan, program yang dibuat mampu menjalankan alat yang dirancang dan hasil monitoring dapat ditampilkan melalui LCD yang mampu memvisualisasikan aktifitas air. Sistem peringatan dini ini mampu bekerja mengukur ketinggian dan intensitas curah hujan dan dapat mengolah data inputan dari sensor juga menampilkan data keadaan sungai. Mikrokontroler juga mampu mengendalikan sistem secara akurat serta data masukan dari sensor dalam melakukan pembacaan nilai ketinggian dan debit air serta intensitas curah hujan dapat dimonitor melalui komputer atau PC.
\end{abstract}

Kata Kunci: Curah Hujan, Debit Air, Ketinggian Air, Monitoring

\section{ABSTRACT}

The river often overflows during the rainy season and floods very detrimental. For the community. Therefore designed a monitoring tool and water discharge and rainfall intensity. This tool is constructed using a combination of water level sensors, ultrasonic sensors (SRF-05) and water flow to produce a monitoring system that provides participation early banji, make a program that can display the results surface monitoring and air discharge. See flood early and learn about the performance of surface monitoring systems and flood air discharge with faster rainfall and understand the microcontroller in measuring and controlling system. Tests carried out with aquarium prototypes and carried out. Measurement for one day on a continuous basis. Test results show that this tool can be updated reminded of flood early efficiently. With Thus, the tool designed is able to monitor the height of water activity, discharge and rainfall in rivers, programs are made capable run the designed tool and the results of monitoring can be accessed through LCD that is able to visualize water activities and this early permit system able to work to measure the height and air discharger rain and be able to implement data input from sensors too displays data on the state of the river so that it can be monitored through a computer. As well as a microcontroller capable of measuring and controlling the system accurately and input data from sensors in height and air discharge measurements as well. Rainfall intensity can be monitored via computer.

Keywords: Rainfall, Water Discharge, Water level, Monitoring 


\section{PENDAHULUAN}

Banjir merupakan salah satu bencana alam yang paling sering terjadi di Indonesia sehingga tidak heran banyak menimbulkan dampak bagi masyarakat. Beberapa dampak yang ditimbulkan adalah terputusnya roda perekonomian di daerah yang terkena banjir, kehilangan tempat tinggal dan harta benda serta banyak anak-anak yang tidak bisa sekolah karena sekolahnya terendam banjir. Salah satu alternatif untuk mengatasi banjir yaitu dengan menggunakan alat pendeteksi banjir. Melalu alat pendeteksi banjir tersebut masyarakat yang berada pada pusat banjir dapat mengetahui dan mengantisifasi lebih awal terjadinya banjir.

Oleh sebab pada penelitian kali ini dibuat suatu sistem peringatan dini banjir menggunakan sensor ultrasonic dan sensor curah hujan berbasis mikrokontroler atmega32. Dimana sistem ini dibuat karena melihat beberapa permasalahan yang diakibatkan oleh banjir, untuk mengantisipasi dampak curah hujan tinggi yang terjadi tiba-tiba. Sehingga dirancang alat ini agar dapat memberikan informasi ke masyarakat sekitar sungai. Sistem ini juga dibuat untuk mengukur ketinggian permukaan, debit air sungai dan curah hujan dengan menggunakan tiga buah sensor yang mana hasil pengukurannya dapat dipantau dan tersimpan dikomputer meskipun data tersebut telah lama tersimpan karena menggunakan database sehingga dapat terus diakses. Apabila dalam keadaan bahaya informasi juga langsung didapatkan dengan adanya alarm tanda bahaya dan juga disertai dengan adanya siaga 1 , siaga 2 dan siaga 3 sebagai lampu indikator peringatan.

\section{LANDASAN TEORI}

\subsection{Water Level Sensor}

Pada penelitian ini menggunakan sensor ultrasonic sebagai water level sensor yang merupakan sensor dengan cara kerja mengubah besaran fisis berupa bunyi menjadi besaran listrik. Menggunakan prinsip dari pantulan suatu gelombang suara dengan frekuensi tertentu dalam menafsirkan jarak suatu benda. Sensor ini menggunakan gelombang ultrasonik (bunyi ultrasonik) sehingga disebut juga sebagai sensor ultrasonic. Sensor ini dapat membaca rentang jangkauan jarak yaitu dari jarak $3 \mathrm{~cm}$ sampai $400 \mathrm{~cm}$ dengan frekuensi $40 \mathrm{kHz}$. Lamanya waktu pembacaan sensor ultrasonic sebanding dengan dua kali jarak sensor dengan obyek. Sensor ultrasonic yang digunakan dalam penelitian ini yaitu SRF-05 yang digunakan dapat dilihat pada gambar 1 di bawah ini:

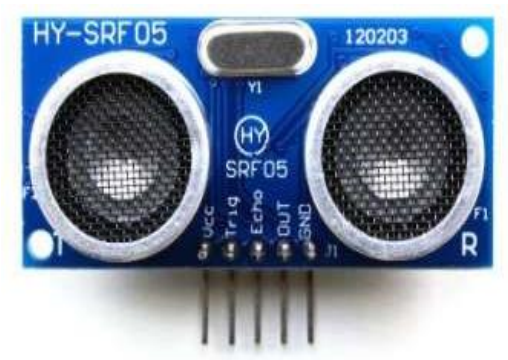

\section{Gambar 1. Sensor Ultrasonik (WaterLevel Sensor)}

\subsection{Water Flow sensor}

Water Flow sensor yaitu sensor yang dapat mendeteksi adanya aliran air yang melewati sebuah sensor. Sensor ini memiliki bagian-bagian yang terdiri dari tubuh katup plastik, rotor air, dan sensor hall-effect. Cara kerja dari sensor ini adalah ketika air mengalir melewati rotor, rotor akan berputar. Kecepatan putaran dari sensor ini dipengaruhi oleh besarnya aliran air yang masuk atau melewati sensor tersebut. Sensor ini tidak akan bekerja atau menghasilkan tegangan apabila sensor belum dialiri 


\section{ALGORITMA: Jurnal Ilmu Komputer dan Informatika}

Volume: 04, Number: 01, April 2020 ISSN 2598-6341 (online)

air dan begitu juga sebaliknya akan menghasilkan tegangan apabila sensor telah dialiri air. Di dalam sensor debit air ini terdapat sensor hall-effect yang akan mengeluarkan output berupa pulsa sesuai dengan besarnya aliran air. Sensor ini memiliki kelebihan yaitu hanya membutuhkan 1 sinyal (SIG) selain jalur 5V DC dan Ground.

\subsection{Raindrop Sensor}

Raindrop sensor atau sensor curah hujan adalah sebuah alat yang dapat mendeteksi adanya hujan yang berada di sekitarnya. Pada sensor curah hujan terdapat raining body, dimana pada saat adanya tetesan air mengenai raining body sensor akan berfungsi sebagai switch. Selain itu sensor curah hujan juga dapat digunakan untuk mengukur intensitas curah hujan. Output analog dari sensor curah hujan digunakan untuk melakukan pendeteksian hujan. Ada dua kondisi pada sensor curah hujan, pada saat tidak mendeteksi hujan nilai output sensor tinggi dan pasa saat mendeteksi hujan kondisi nilai output sensor rendah.

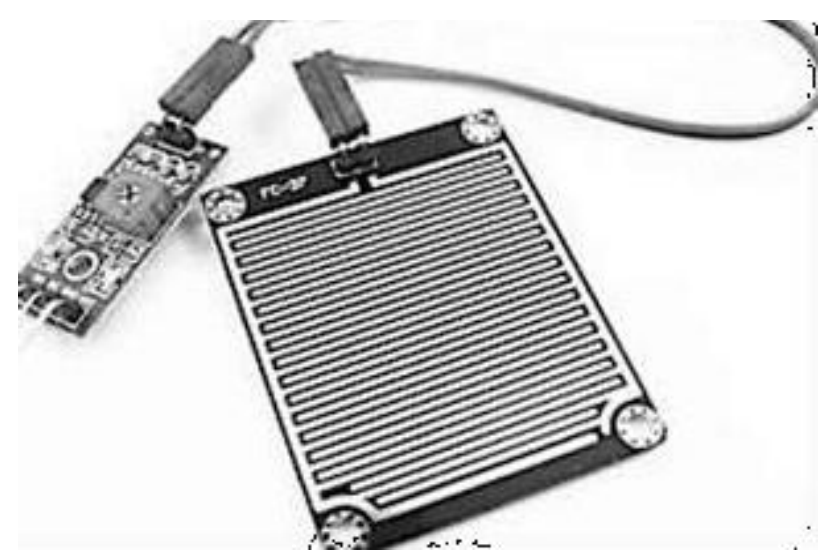

Gambar 2. Raindrop Sensor (Sensor Curah Hujan)

\subsection{Mikrokontroler}

Mikrokontroler atau disebut juga pengontrol tertanam (embeddedcontroller) merupakan suatu sistem yang terdiri dari input dan output, memori, dan prosesor yang digunakan pada produk seperti mesin cuci, pemutar video, mobil dan telepon. Pada penelitian ini, mikrokontroler yang digunakan yaitu Atmega32. Mikrokontroler ini memiliki memori yang cukup banyak, sehingga kita dapat membuat program tanpa takut kehabisan memori dan paling efektif dalam membuat sebuah sistem.

\section{METODOLOGI PENELITIAN}

Secara umum metode yang digunakan dalam penelitian ini terdiri atas perancangan perangkat keras dan perancangan perangkat lunak pada sistem monitoring permukaan dan debit air sungai serta intensitas curah hujan sebagai peringatan dini banjir berbasis mikrokontroler atmega32.

\subsection{Perancangan Perangkat Keras (hardware)}

Perancangan perangkat keras terdiri atas dua bagian utama, yaitu perancangan sistem mekanik dan perncangan sistem elektrik. Perancangan mekanik terdiri atas bentuk atau desain fisik sistem, sedangkan perancangan elektrik terdiri atas perancangan sistem rangkaian elektrik dan sensor. Gambar 4 menunjukkan rangkaian mekanik sistem yang digunakan dan gambar 5 menunjukkan diagram blok untuk desain perangkat keras (hardware) secara keselurhan. 


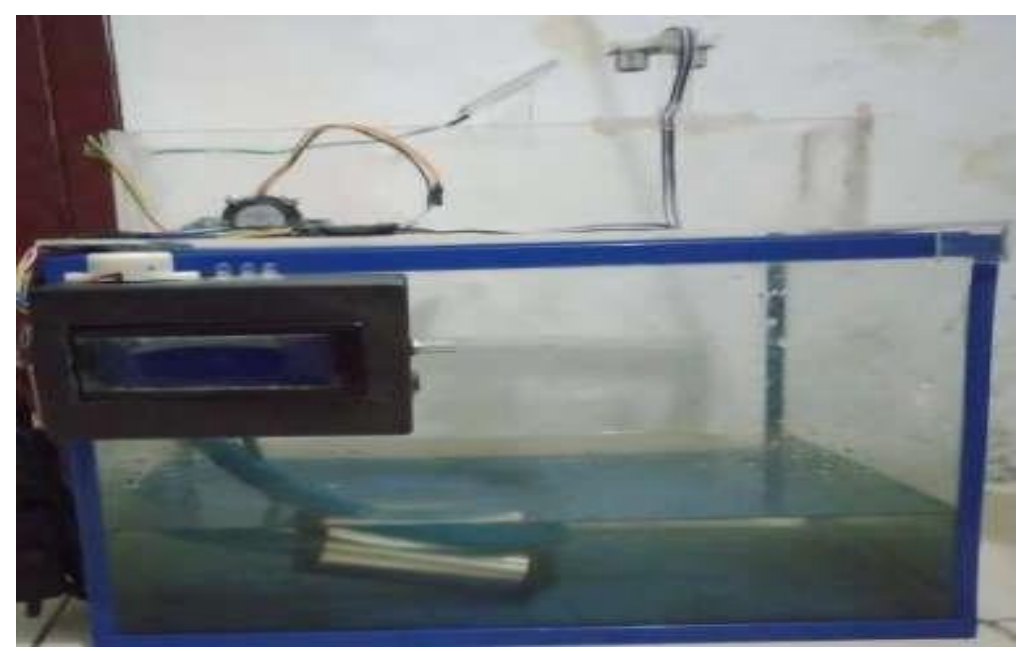

Gambar 3. Perancangan Mekanik Sistem

Pada perancangan mekanik di atas digunakan bahan akrilik, plastic dikarenakan bahan ini kuat dan tidak mudah pecah, ditambahkan dengan bahan-bahan pendukung lain seperti timah, kabel dan sebagainya.

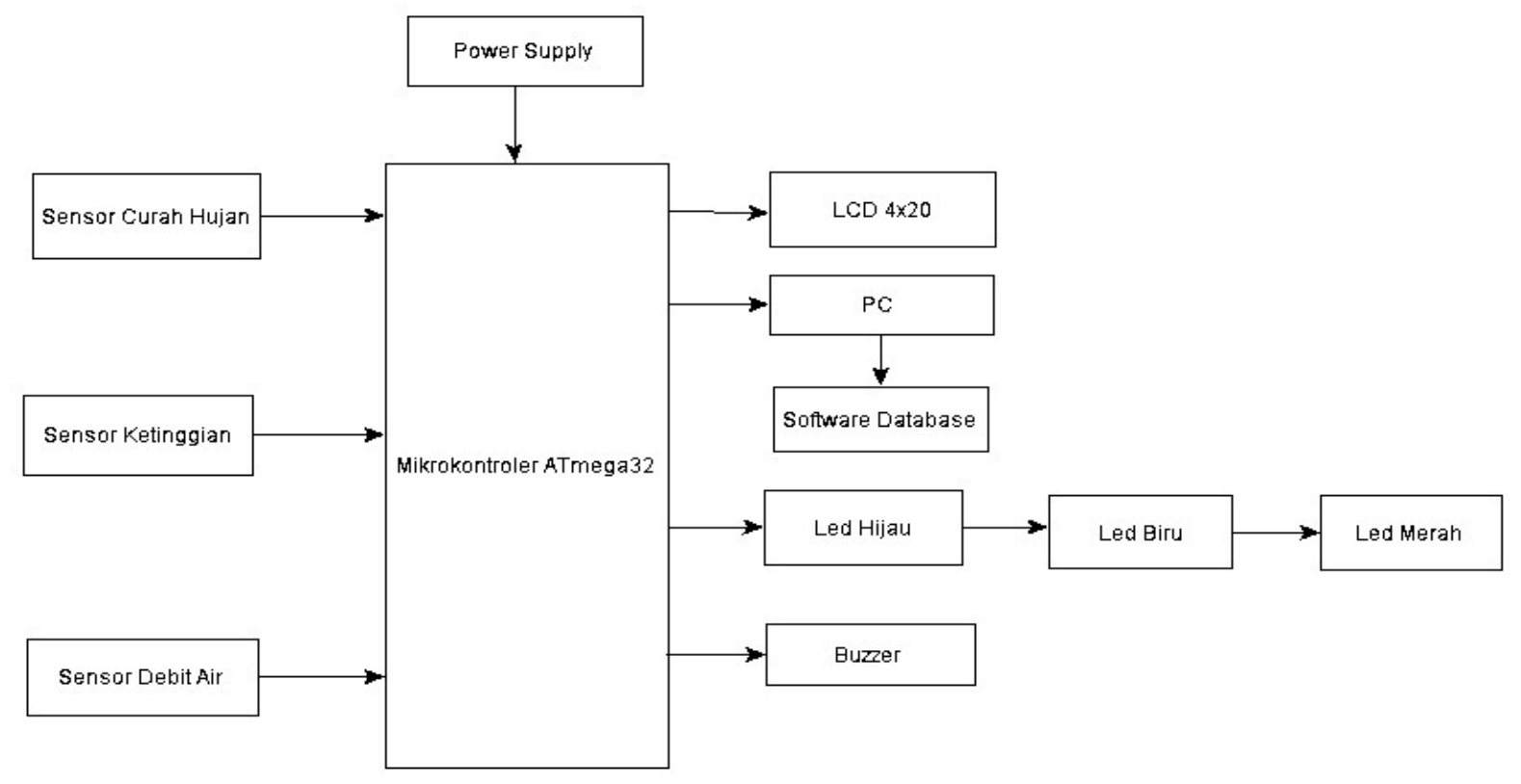

Gambar 4. Diagram Blok Keseluruhan Sistem

Fungsi kerja dari masing-masing blok perangkat keras (hardware) diatas adalah sebagai berikut:

a. Blok power supply difungsikan sebagai sumber tegangan keseluruhan sistem, besar tegangan keluaran dari alat ini sebesar 5 volt.

b. Blok sensor yang terdiri dari sensor curah hujan untuk mendeteksi banyaknya curah hujan yang turun dalam satuan $(\mathrm{mm})$, sensor ketinggian untuk mendeteksi ketinggian permukaan air dalam satuan $(\mathrm{cm})$ dan sensor debit air untuk mendeteksi debit air dalam satuan (L/det).

c. Blok mikrokontroler ATmega32 difungsikan sebagai pengendali keseluruhan sistem.

d. Blok LCD difungsikan untuk menampil data di monitor 


\section{ALGORITMA: Jurnal Ilmu Komputer dan Informatika}

Volume: 04, Number: 01, April 2020 ISSN 2598-6341 (online)

e. Blok database difungsikan sebagai penyimpan dan monitoring data.

f. Blok LED yang terdiri dari led hijau yaitu sebagai siaga tiga, led biru sebagai siaga dua, dan led merah sebagai satu.

g. Blok buzzer difungsikan sebagai alarm jika berada di titik bahaya.

\subsection{Perancangan Perangkat Lunak}

Perancangan perangkat lunak (software) menggunakan pemrograman bahasa $\mathrm{C}$ dengan Code Vision AVR sebagai software utama pemrograman pada sistem monitoring permukaan dan debit air sungai serta intensitas curah hujan sebagai peringatan dini banjir berbasis mikrokontroler atmega32.

\section{HASIL DAN PEMBAHASAN}

Hasil yang dibahas pada penelitian ini meliputi pengujian sensor hujan, pengujian debit air, pengujian sensor curah hujan pengujian alat peringatan dini banjir. Hasil desain sistem yang telah dirancang pada gambar 5 .

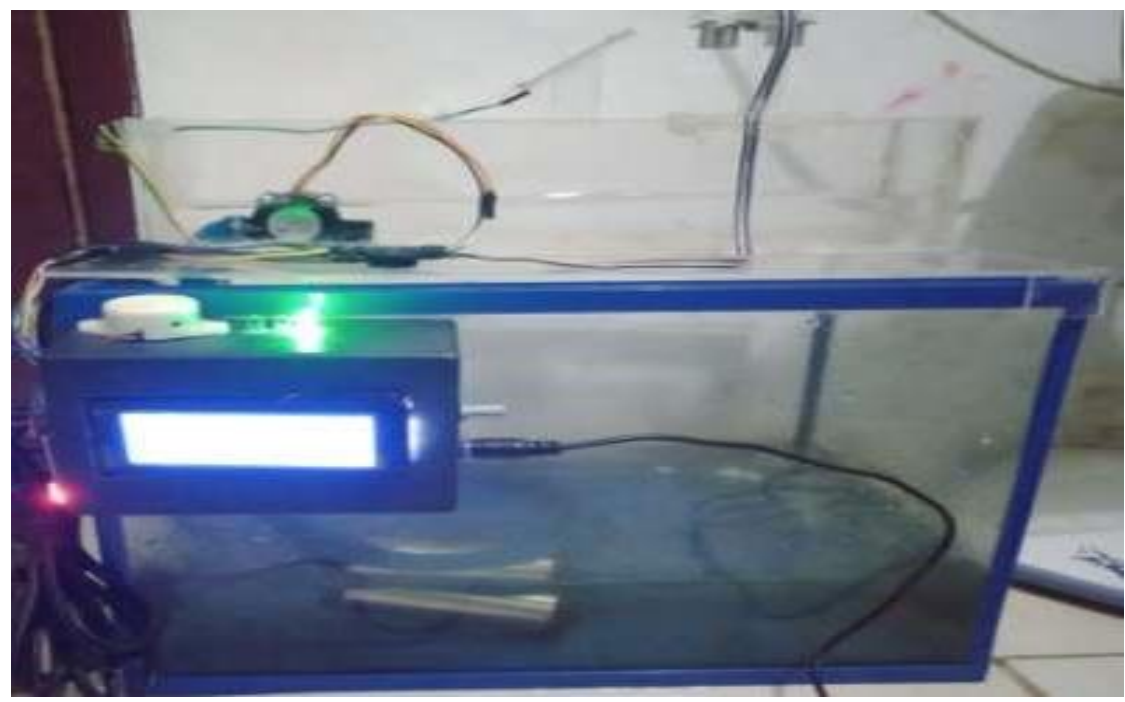

Gambar 5. Hasil Rancangan Sistem Sensor Secara Keseluruhan

\subsection{Pengujian sensor hujan}

Pengujian rangkain sensor hujan dengan cara meletakkan sensor tidak (terhubung kemikrokontroler) di atas wadah aquarium, sensor yang terletak diatas wadah aquarium akan mendeteksi hujan apabila ada tetesan air yang jatuh ke atas permukaan sensor hujan dan pembacaan dapat dilihat pada tampilan di LCD yang menunjukkan hasil pengukuran curah hujan yang terbaca oleh sensor dan ditampilkan di LCD sebesar 264.0 dalam satuan mm. 264,0 mm menandakan gerimis karena hujan gerimis memiliki rentang $200 \mathrm{~mm}-650 \mathrm{~mm}$.

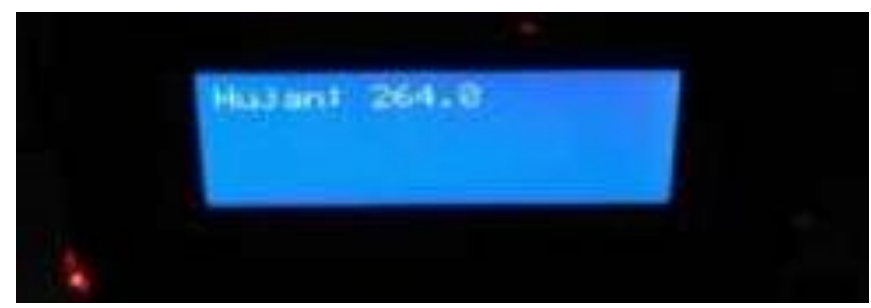




\section{ALGORITMA: Jurnal Ilmu Komputer dan Informatika}

Volume: 04, Number: 01, April 2020 ISSN 2598-6341 (online)

Gambar 6. Tampilan LCD pada Pengujian Sensor Hujan

\subsection{Pengujian Sensor Debit Air}

Pengujian rangkaian sensor debit air dengan cara memasukkan sensor (terhubung ke mikrokontroler) kedalam wadah aquarium yang berisi air, sensor debit air akan mendeteksi kecepatan air yang masuk ke dalam wadah melalui selang atau pipa yang menghubungkan sensor dengan wadah serta dapat membaca volume air yang masuk ke dalam wadah dan pembacaan dapat dilihat pada tampilan di LCD. Untuk melihat hasil pengukuran sensor debit dan keakurasiannya dapat dilihat pada Tabel 1, di bawah ini

Tabel 1. Keakurasian Sensor Debit Air

\begin{tabular}{ccccc}
\hline $\begin{array}{c}\text { Pembacaan } \\
\text { sensor debit } \\
\text { (Praktek) }\end{array}$ & $\begin{array}{c}\text { Pembuktian rumus } \\
\text { debit (teori) }\end{array}$ & $\begin{array}{c}\text { Selisih teori } \\
\text { dan } \\
\text { pengukuran }\end{array}$ & \% ralat & Akurasi \\
\hline $0,2 \mathrm{l} / \mathrm{det}$ & $0,22 \mathrm{l} / \mathrm{det}$ & $0,02 \mathrm{l} / \mathrm{det}$ & $9 \%$ & $91 \%$ \\
$0,4 \mathrm{l} / \mathrm{det}$ & $0,46 \mathrm{l} / \mathrm{det}$ & $0,06 \mathrm{l} / \mathrm{det}$ & $13 \%$ & $87 \%$ \\
$0,6 \mathrm{l} / \mathrm{det}$ & $0,55 \mathrm{l} / \mathrm{det}$ & $0,05 \mathrm{l} / \mathrm{det}$ & $9 \%$ & $91 \%$ \\
$0,7 \mathrm{l} / \mathrm{det}$ & $0,68 \mathrm{l} / \mathrm{det}$ & $0,021 / \mathrm{det}$ & $3 \%$ & $97 \%$ \\
$0,8 \mathrm{l} / \mathrm{det}$ & $0,84 \mathrm{l} / \mathrm{det}$ & $0,04 \mathrm{l} / \mathrm{det}$ & $5 \%$ & $95 \%$ \\
\hline
\end{tabular}

\subsection{Pengujian sensor ultrasonic}

Pengujian rangkaian sensor ultrasonik dilakukan dengan cara meletakkan sensor di atas wadah yang berisi air, sensor akan mendeteksi ketinggian air yang masuk ke dalam wadah serta perubahan ketinggian dan pembacaan dapat dilihat pada tampilan di LCD. Untuk melihat hasil pengukuran sensor ultrasonic dan keakurasiannya dapat dilihat pada Tabel 2, di bawah ini:

Tabel 2. Keakurasian Sensor Ultrasonik

\begin{tabular}{ccccc}
\hline $\begin{array}{c}\text { Pengukuran } \\
\text { sensor ultrasonik } \\
\text { (Praktek) }\end{array}$ & $\begin{array}{c}\text { Pengukuran mistar } \\
\text { (Teori) }\end{array}$ & $\begin{array}{c}\text { Selisih teori } \\
\text { dan } \\
\text { pengukuran }\end{array}$ & \% ralat & Akurasi \\
\hline $0,9 \mathrm{~cm}$ & $1 \mathrm{~cm}$ & 0,1 & $10 \%$ & $90 \%$ \\
$1,7 \mathrm{~cm}$ & $2 \mathrm{~cm}$ & 0,3 & $15 \%$ & $85 \%$ \\
$2,6 \mathrm{~cm}$ & $3 \mathrm{~cm}$ & 0,4 & $13 \%$ & $87 \%$ \\
$3,4 \mathrm{~cm}$ & $4 \mathrm{~cm}$ & 0,6 & $15 \%$ & $85 \%$ \\
\hline
\end{tabular}


Volume: 04, Number: 01, April 2020 ISSN 2598-6341 (online)

$\begin{array}{lllll}4,3 \mathrm{~cm} & 5 \mathrm{~cm} & 0,7 & 14 \% & 86 \%\end{array}$

\subsection{Pengujian Rangkaian Akusisi Data FTDI}

Akusisi data dilakukan dengan menggunakan FTDI yang tersambung ke laptop dan data ketinggian permukaan, debit air dan curah hujan akan terecord kedalam laptop mengunakan software PLX-DAQ. Data akan ditampilkan di LCD dan di laptop. Database plx.daq software yang digunakan untuk mencatat data hasil monitoring peringatan dini banjir yang terdiri dari data ketinggian air, debit air, volume serta curah hujan. Yang kemudian dikirim oleh mikrokontroler ke komputer dan ditampilkan di Ms. excel.

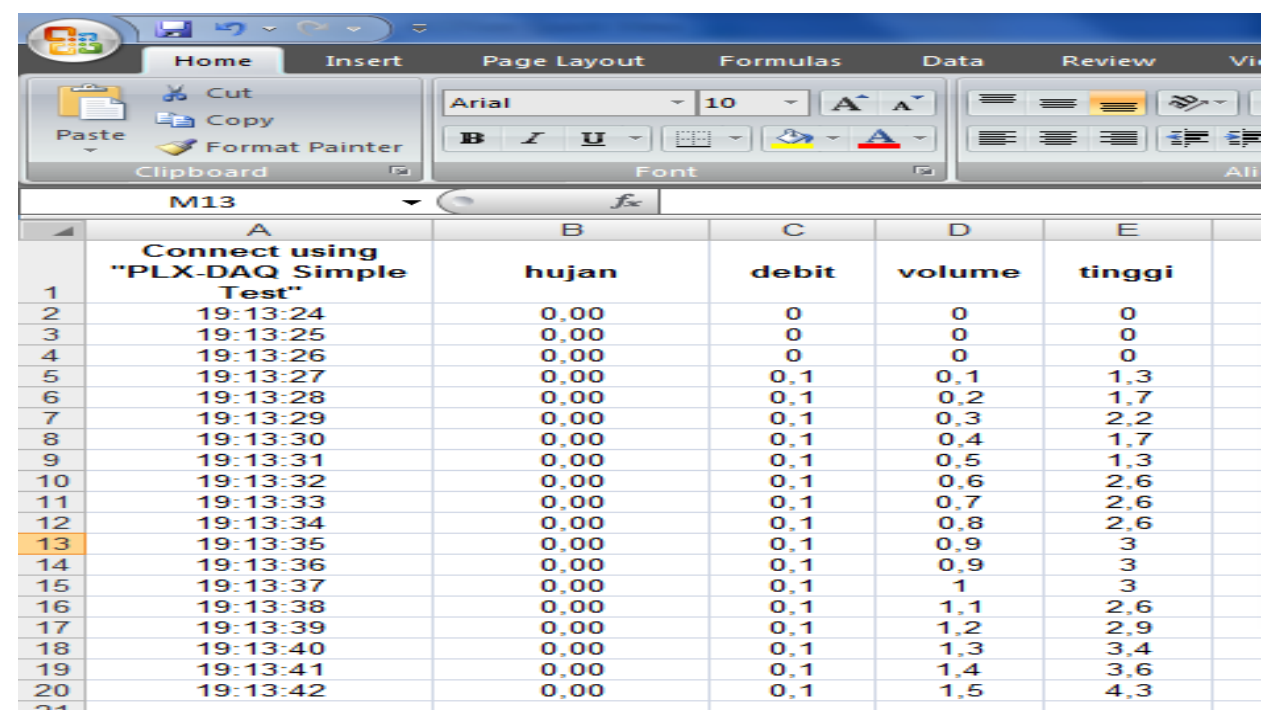

Gambar 7. Pengujian Rangkaian Akusisi Data FTDI

\section{KESIMPULAN}

Hasil ujicooba sistem peringatan dini baniir menggunakan sensor ultrasonic dan sensor curah hujan berbasis mikrkontroler atmega32 yang dilakukan membuktikan bahwa sistem peringatan dini ini mampu bekerja mengukur ketinggian dan intensitas curah hujan dan mampu mengimplementasikan data masukan dari sensor juga menampilkan data keadaan sungai sehingga dapat dipantau melalui komputer. Mikrokontroler mampu mengendalikan sistem secara akurat dengan keakurasian rata-rata diatas $85 \%$ serta data masukan dari sensor dalam pengukuran ketinggian dan intensitas curah hujan dapat dipantau melalui komputer. Untuk menyempurnakan alat peringatan dini banjir ini, ada beberapa hal yang dijadikan saran untuk penelitian selanjutnya diharapkan untuk pengembangan selanjutnya alat sistem monitoring ketinggian permukaan dan intensitas curah hujan ini tidak lagi menggunakan daya dari listrik PLN lagi tetapi sudah harus menggunakan panel surya sebagai dayanya. Agar ketika mati lampu sistem monitoring ini tetap bisa menyimpan data.

\section{DAFTAR PUSTAKA}

[1] Ahmad, Mirza. 2017. Rancang bangun Alat Pengukur Curah Hujan Jarak Jauh dengan Short Massage Service(SMS) Gateway Berbasis Mikrokontroler[skrispi]. Palembang: Politeknik Negeri Sriwijaya. 


\section{ALGORITMA: Jurnal Ilmu Komputer dan Informatika}

Volume: 04, Number: 01, April 2020 ISSN 2598-6341 (online)

[2] Akhiruddin. 2018.Rancang Bangun Alat Pendeteksi Ketinggian Air Sungai Sebagai Peringatan Dini Banjir Berbasis Arduino Nano. Jurnal of Electrical Technology.3(3):174.

[3] E.Z, Nugroho. 2018. Sistem Monitoring Ketinggian Air Menggunakan Mikrokontroler Atmega32, Sensor Ultrasonik SRF-05 Dan SMS [skripsi]. Kediri:Universitas Nusantara PGRI Kediri.

[4] Ginting, Segel, William M. Putuhena. 2014. Sistem Peringatan Dini Banjir Jakarta Jakarta-Flood Early Warning System (J-Fews). Jurnal Sumber Daya Air.10(1):72-73.

[5] Khairul Ilham.2018. Alat penyiraman tanaman otomatis berdasarkan waktu dan kelembaban tanah berbasis mikrokontroler [skripsi].Medan:Universitas Sumatera Utara.

[6] Mardani. 2016. Pembuatan Alat Ukur Debit Air Menggunakan Sensor Aliran Berbasis Mikrokontroler Atmega328P. Pillar Of Physics. 8: 105.

[7] Maria Sova.2017. Rancang bangun alat ukur curah hujan dengan metode timbangan menggunakan sensor fototransistor berbasis arduino uno[skripsi].Bandar Lampung: Universitas Lampung.

[8] Mirza Ahmad. 2017. Rancang bangun Alat Pengukur Curah Hujan Jarak Jauh dengan Short Massage Service(SMS) Gateway Berbasis Mikrokontroler[skrispi]. Palembang: Politeknik Negeri Sriwijaya.

[9] Sova, Maria.2017. Rancang bangun alat ukur curah hujan dengan metode timbangan menggunakan sensor fototransistor berbasis arduino uno[skripsi]. Bandar Lampung: Universitas Lampung.

[10] Yuliawiyata, Rana. 2013. Prototipe sistem pngukuran ketinggian dan debit air pada sungai berbasis mikrokontroler Atmegal6 [skripsi]. Yogyakarta: Universitas Islam Negeri Sunan Kalijaga 